\title{
Safety and Efficacy of Exenatide Once Weekly in Participants with Type 2 Diabetes and Stage 2/3 Chronic Kidney Disease
}

\author{
Cristian Guja · Juan P. Frías · Lisa Suchower • Elise Hardy • \\ Galina Marr · C. David Sjöström · Serge A. Jabbour
}

Received: February 20, 2020 / Published online: April 18, 2020

(C) The Author(s) 2020

\begin{abstract}
Introduction: The safety and efficacy of exenatide once weekly (EQW) is overall well established. EQW is primarily renally eliminated. In this study, the efficacy and renal and gastrointestinal tolerability of EQW were summarised in participants with type 2 diabetes and chronic kidney disease stage 3 (CKD3; moderate renal
\end{abstract}

Enhanced Digital Features To view enhanced digital features for this article go to https://doi.org/10.6084/ m9.figshare.12059103.

Electronic supplementary material The online version of this article (https://doi.org/10.1007/s13300020-00815-z) contains supplementary material, which is available to authorized users.

C. Guja ( $\square)$

"Carol Davila" University of Medicine and

Pharmacy, Bucharest, Romania

e-mail: cristian.guja@b.astral.ro

J. P. Frías

National Research Institute, Los Angeles, CA, USA

L. Suchower

Kelly Services, Gaithersburg, MD, USA

E. Hardy · G. Marr

AstraZeneca, Gaithersburg, MD, USA

C. D. Sjöström

AstraZeneca, Gothenburg, Sweden

S. A. Jabbour

Thomas Jefferson University, Philadelphia, PA, USA impairment; estimated glomerular filtration rate $[\mathrm{eGFR}] \geq 30$ to $<60 \mathrm{~mL} / \mathrm{min} / 1.73 \mathrm{~m}^{2}$ ) or CKD stage 2 (CKD2; mild renal impairment; eGFR $\geq 60$ to $<90 \mathrm{~mL} / \mathrm{min} / 1.73 \mathrm{~m}^{2}$ ).

Methods: Data on participants with type 2 diabetes and baseline CKD3 or CKD2 from eight phase 3, double-blind or open-label studies with 26- or 28-week controlled treatment periods were pooled. Participants received EQW or a placebo/non-glucagon-like peptide-1 receptor agonist comparator (sitagliptin, metformin, pioglitazone, dapagliflozin and insulin).

Results: Participants with baseline CKD3 $(N=182)$ or CKD2 $(N=772)$ receiving EQW differed in a number of baseline characteristics, such as age $<65$ years, race, mean body mass index and mean type 2 diabetes duration, whereas mean blood pressure and glycated haemoglobin $\left(\mathrm{HbA}_{1 \mathrm{c}}\right)$ were similar. Mean reductions in $\mathrm{HbA}_{1 \mathrm{c}}$, body weight and systolic blood pressure from baseline to week 26/28 in participants receiving EQW were similar between the CKD subgroups. The proportions of participants (CKD3 and CKD2) with any adverse event (AE) were $81 \%$ and $72 \%$, respectively, for EQW and $74 \%$ and $68 \%$, respectively, for all comparators; those for serious AEs were 2.7\% and $3.4 \%$, respectively, for EQW and $6 \%$ and $5 \%$, respectively, for all comparators. Gastrointestinal $\mathrm{AE}$ rates were higher in the EQW CKD3 subgroup $(42.2 \%$ of participants) than in the CKD2 (32.8\%) subgroup, although rates for nausea and vomiting were similar. There were 
no dehydration events; one participant in each treatment group had a serious AE of acute kidney injury (EQW with $\mathrm{CKD} 3, n=1$; pioglitazone with CKD2, $n=1$ ).

Conclusion: Exenatide once weekly was well tolerated and demonstrated similar efficacy in participants with type 2 diabetes with mild and moderate renal impairment.

Trial Registration: ClinicalTrials.gov identifiers: NCT00637273, NCT00676338, NCT02229383, NCT02229396, NCT00641056, NCT01652729, NCT00935532, NCT01003184.

Keywords: Chronic renal insufficiency; CKD2; CKD3; Exenatide; Glucagon-like peptide 1; Pooled analysis; Safety; Type 2 diabetes mellitus

\section{Key Summary Points}

\section{Why carry out this study?}

Exenatide once weekly (EQW) has a wellestablished safety and efficacy profile and is primarily renally eliminated.

The safety profile of EQW is well established in people with chronic kidney disease stage 2 (CKD2; mild renal impairment); in the current analysis, we therefore compared this safety profile with data from people with CKD stage 3 (CKD3; moderate renal impairment).

We evaluated the efficacy and renal and gastrointestinal tolerability of EQW in patients with type 2 diabetes and CKD (CKD3 vs. CKD2).

\section{What was learned from the study?}

Pooled analysis of eight phase 3, 26/28week, double-blind or open-label studies of EQW showed it to be well-tolerated and with similar efficacy in participants with type 2 diabetes who also had mild or moderate renal impairment.

The study provides users and healthcare providers with further knowledge on exenatide's tolerability and efficacy in people with type 2 diabetes and different degrees of renal impairment.

\section{INTRODUCTION}

Type 2 diabetes is the most common cause of chronic kidney disease (CKD) in developed countries [1]. Exenatide is a glucagon-like peptide-1 receptor agonist (GLP-1 RA) used for the treatment of hyperglycaemia in people with type 2 diabetes [2]. The safety and efficacy of exenatide once weekly (EQW) administered as a subcutaneous injection are well established in the general population with type 2 diabetes [2]. Exenatide has not been shown to have any direct nephrotoxic effects $[3,4]$, but it is predominantly metabolised by proteolytic degradation after renal filtration [5]. A reduced clearance could therefore lead to an increased frequency of gastrointestinal adverse events (AEs) in people with severe renal impairment, potentially leading to dehydration and an increased risk for acute kidney injury.

People with mild or moderate renal impairment, compared with those with normal renal function, have also been reported to have an increase in EQW exposure [3, 5] (although not to a clinically relevant degree). As exenatide is the first once-weekly GLP-1 RA to be commercially available, there has been a strong focus on its gastrointestinal and renal AE profile. Because regulatory authorities have been inconsistent when considering the suitability of EQW in people with CKD $[3,5,6]$, there is a strong rationale to re-evaluate EQW's risk-benefit profile in people with type 2 diabetes who have CKD at different stages. Such a re-evaluation is especially relevant given that data from the EXSCEL (Exenatide Study of Cardiovascular Event Lowering) trial, which included participants with an estimated glomerular filtration rate (eGFR) as low as $30 \mathrm{~mL} / \mathrm{min} / 1.73 \mathrm{~m}^{2}$, suggest a possible positive effect of EQW on CKD progression (i.e. significant reduction in an adjusted composite outcome of $40 \%$ eGFR decline, new macroalbuminuria, renal replacement therapy or renal death) [7]. It is also important to compare the tolerability of EQW with that of other anti-hyperglycaemic drugs in renally impaired people with type 2 diabetes.

Because the safety profile of EQW is well established in people with CKD 
stage 2 (CKD2; mild renal impairment; eGFR $\geq 60$ to $<90 \mathrm{~mL} / \mathrm{min} / 1.73 \mathrm{~m}^{2}$ ) [8], in the analysis reported here we compared this profile using data from people with CKD stage 3 (CKD3; moderate renal impairment; eGFR $\geq 30$ to $<60 \mathrm{~mL} / \mathrm{min} / 1.73 \mathrm{~m}^{2}$ ) who received treatment with EQW or a placebo/ non-GLP-1 RA comparator. The objective of this study was, therefore, to summarise the efficacy and tolerability of EQW in terms of renal and gastrointestinal AEs in people with type 2 diabetes with CKD3 or CKD2.

\section{METHODS}

\section{Study Design and Participant Populations}

This post hoc analysis evaluated the pooled safety and efficacy data from eight previously published double-blind or open-label studies [9-16] (see Electronic Supplementary Material [ESM] Table S1). The studies included participants with mild or moderate baseline CKD who were treated with EQW, placebo or sitagliptin, metformin, pioglitazone, dapagliflozin or insulin.

The rationale for selecting these eight studies for pooling was based on the following criteria: (1) all studies (four open-label, four doubleblind) were phase 3 safety and efficacy studies with a controlled treatment period of 2628 weeks (to reflect an adequate treatment period for assessment; results were combined for the week 26/28 endpoint); (2) all studies included a treatment group with EQW in either of the two currently available formulations (aqueous formulation or non-aqueous suspension, both $2 \mathrm{mg}$, administered subcutaneously once weekly); (3) all studies included a comparator group(s) (active or placebo) other than another GLP-1 RA (studies with only another GLP-1 RA as a comparator were excluded to provide an objective view of EQW's GLP-1-related effect in relation to renal function).

Only the controlled treatment periods were analysed because in some studies participants taking comparators were switched to EQW for the extension period and the lengths of the extension periods varied between studies.
Participants were pooled across the eight studies and classified into two treatment groups: (1) EQW and (2) all comparators. Participants were also classified into two subgroups based on the baseline eGFR value, namely CKD3 and CKD2, with eGFR estimated using the 4-variable Modification of Diet in Renal Disease (MDRD-4) formula [17] or the 3-variable Japanese equation [18] (for study GWBX [15] conducted in Japan), to provide more reliable eGFR calculations in Japanese participants.

All studies complied with the Helsinki Declaration of 1964 and its later amendments, and other relevant ethical guidelines, and all participants had provided written informed consent. Each study site involved in the eight studies received approval of their respective local ethics committees.

\section{Outcome Measures}

\section{Efficacy}

Efficacy was evaluated by the absolute change from baseline to the end of the 26-/28-week controlled period for glycated haemoglobin $\left(\mathrm{HbA}_{1 \mathrm{c}}\right)$, body weight and sitting systolic blood pressure (SBP).

\section{Safety}

The proportions of participants with AEs, AEs leading to discontinuation of treatment, serious AEs and AEs of special interest (AESIs; i.e. acute renal failure and dehydration-related events, hypoglycaemia and gastrointestinal events) during the 26/28-week controlled treatment period were calculated and presented by treatment group and CKD subgroup. The Medical Dictionary for Regulatory Activities (MedDRA) version 21.1 (https://www.meddra.org/) was used for AE coding. AEs were recorded throughout the studies, and AESIs were evaluated by summarising AEs using Standardised MedDRA Queries (SMQs; for dehydration and acute renal failure) or by system organ class and preferred terms (for gastrointestinal AEs). Events of major hypoglycaemia were defined according to each study's criteria; further details can be found in the ESM.

The crude AE incidence rate was calculated as the total number of participants in a pooled treatment group with an AE divided by the total 
number of participants in that pooled treatment group. Study size-adjusted rates (based on giving each study a weight) were also calculated to account for imbalances in randomisation ratios in two of the studies $[13,16]$. However, only the crude rates are presented because they were similar to the study size-adjusted rates.

Heart rate and laboratory results, including eGFR and urinary albumin-to-creatinine ratio, are presented as baseline and week 26/28 change from baseline results.

\section{Statistical Analyses}

Two participant populations were defined for these analyses: (1) the safety analysis set, which was defined as all participants who were randomised and took at least one dose of the study medication; participants were analysed as treated rather than as randomised (used for safety results); and (2) the intention-to-treat (ITT) analysis set, which was defined as all randomised participants who received at least one dose of study medication and had at least one post-baseline $\mathrm{HbA}_{1 \mathrm{c}}$ assessment; participants were analysed as randomised rather than as treated (used for participant demographics/ baseline characteristics and efficacy results).

$\mathrm{HbA}_{1 \mathrm{c}}$, body weight, SBP and eGFR results at baseline and week $26 / 28$ and change in results from baseline to week 26/28 were summarised descriptively (mean, standard deviation); an analysis of covariance model that included treatment group and study as fixed effects and the continuous baseline value of the variable as a covariate was also used to analyse the changefrom-baseline results. Point estimates (least squares mean estimates, standard errors) and corresponding two-sided 95\% confidence intervals (CIs) for absolute change from baseline to week $26 / 28$ were derived. Baseline was defined as the latest non-missing assessment prior to the first dose of randomised study medication. For the analysis of post-baseline results, only those results collected during the week $26 / 28$ controlled period were included in the analysis (i.e. an all-completers analysis). No imputation was conducted for missing week $26 / 28$ results.

Three studies (DURATION-7, DURATION-8 and BCB120) [12-14] offered participants rescue medication (prandial insulin, basal insulin and glucose-lowering therapy, respectively). Efficacy results after rescue medication use in these studies were excluded for the $\mathrm{HbA}_{1 \mathrm{c}}$ and body weight analyses but not for the SBP and eGFR analyses because the rescue medication theoretically should not affect these measurements. The other five studies did not specifically offer rescue medications to the participants. All results after treatment discontinuation were excluded.

All statistical analyses were performed using SAS version 9.4 (SAS Institute, Cary, NC, USA).

\section{RESULTS}

\section{Participant Demographics and Baseline Characteristics}

Participants with CKD3 $(N=182)$ or CKD2 $(N=772)$ at baseline receiving EQW differed in a number of baseline characteristics, including age $<65$ years $(56 \%$ vs. $79 \%$, respectively), mean body mass index $\left(28.3\right.$ vs. $31.6 \mathrm{~kg} / \mathrm{m}^{2}$, respectively) and mean duration of type 2 diabetes (9.7 vs. 7.6 years, respectively), whereas mean blood pressure $(133 / 77$ vs. $131 / 79 \mathrm{mmHg}$, respectively) and mean $\mathrm{HbA}_{1 \mathrm{c}}(8.3 \%$ vs. $8.5 \%$, respectively) were similar (Table 1 ). The safety analysis set produced similar values to the ITT analysis set (data not shown).

Participants with CKD3 receiving EQW were mostly Asian (61\% vs. 20\% with CKD2) as 59\% were from a study conducted in Japan [15].

Median treatment duration was similar between participants receiving EQW with CKD3 (183 days) and CKD2 (189 days).

\section{Efficacy}

Mean changes from baseline to week 26/28 in $\mathrm{HbA}_{1 \mathrm{c}}$, body weight and SBP were similar between the CKD3 and CKD2 subgroups for participants receiving EQW. Both CKD subgroups of participants receiving EQW had clinically meaningful adjusted mean reductions in $\mathrm{HbA}_{1 \mathrm{c}}$. Adjusted mean reductions were also observed for body weight and SBP, independent of the stage of renal impairment (Fig. 1; Table 2). 
Table 1 Demographics and baseline characteristics for participants with type 2 diabetes by baseline chronic kidney disease category-8-study pool (intention-to-treat analysis set)

\begin{tabular}{|c|c|c|c|c|}
\hline \multirow[t]{2}{*}{ Characteristic } & \multicolumn{2}{|l|}{ CKD3 } & \multicolumn{2}{|l|}{ CKD2 } \\
\hline & $\begin{array}{l}\mathrm{EQW} \\
(N=182)\end{array}$ & $\begin{array}{l}\text { All comparators } \\
(N=207)\end{array}$ & $\begin{array}{l}\text { EQW } \\
(N=772)\end{array}$ & $\begin{array}{l}\text { All comparators } \\
(N=1043)\end{array}$ \\
\hline Men, $n(\%)$ & $105(57.7)$ & $105(50.7)$ & $419(54.3)$ & $608(58.3)$ \\
\hline \multicolumn{5}{|l|}{ Age (years) } \\
\hline Mean (SD) & $62.5(9.0)$ & $62.2(9.0)$ & $56.9(9.3)$ & $56.9(9.5)$ \\
\hline$<65, n(\%)$ & $102(56.0)$ & $120(58.0)$ & $613(79.4)$ & $820(78.6)$ \\
\hline \multicolumn{5}{|l|}{ Race, $n(\%)$} \\
\hline White & $66(36.3)$ & $89(43.0)$ & $522(67.6)$ & $685(65.7)$ \\
\hline Asian & $111(61.0)$ & $106(51.2)$ & $157(20.3)$ & $227(21.8)$ \\
\hline Black or African American & 0 & $5(2.4)$ & $38(4.9)$ & $39(3.7)$ \\
\hline Body weight $(\mathrm{kg})$, mean $(\mathrm{SD})$ & $76.9(19.3)$ & $78.5(17.7)$ & $88.8(19.3)^{\mathrm{a}}$ & $87.8(19.1)$ \\
\hline BMI $\left(\mathrm{kg} / \mathrm{m}^{2}\right)$, mean $(\mathrm{SD})$ & $28.3(5.1)$ & $29.6(5.8)$ & $31.6(5.5)^{\mathrm{a}}$ & $31.4(5.6)$ \\
\hline $\mathrm{BMI} \geq 35\left(\mathrm{~kg} / \mathrm{m}^{2}\right), n(\%)$ & $24(13.2)$ & $40(19.3)$ & $196(25.4)$ & $246(23.6)$ \\
\hline Sitting SBP $(\mathrm{mm} \mathrm{Hg})$, mean $(\mathrm{SD})$ & $133(14.3)$ & $136(17.2)$ & $131(13.8)$ & $131(14.6)$ \\
\hline Sitting DBP $(\mathrm{mm} \mathrm{Hg})$, mean $(\mathrm{SD})$ & $77(9.7)$ & $79(9.6)$ & $79(9.3)$ & $79(8.8)$ \\
\hline eGFR $\left(\mathrm{mL} / \mathrm{min} / 1.73 \mathrm{~m}^{2}\right)$, mean $(\mathrm{SD})$ & $52.7(5.6)$ & $53.3(5.1)$ & $75.9(8.4)$ & $75.9(8.6)$ \\
\hline \multirow[t]{3}{*}{ uACR $(\mathrm{mg} / \mathrm{g})$, mean $(\mathrm{SD})$, median } & 105 (348), & $116(438)$ & $54.1(171)$ & $47.9(158)$ \\
\hline & 14.2 & 20.4 & 10.6 & 10.6 \\
\hline & $n=151$ & $n=165$ & $n=528$ & $n=810$ \\
\hline$<30 \mathrm{mg} / \mathrm{g}$ (normal), $n(\%)$ & $96(52.7)$ & $108(52.2)$ & $398(51.6)$ & $609(58.4)$ \\
\hline $\begin{array}{l}\geq 30 \text { to } \leq 300 \mathrm{mg} / \mathrm{g} \text { (moderately increased } \\
\text { albuminuria), } n(\%)\end{array}$ & $45(24.7)$ & $46(22.2)$ & $108(14.0)$ & $178(17.1)$ \\
\hline $\begin{array}{l}>300 \mathrm{mg} / \mathrm{g} \text { (severely increased albuminuria), } \\
n(\%)\end{array}$ & $10(5.5)$ & $11(5.3)$ & $22(2.8)$ & $23(2.2)$ \\
\hline Unknown $^{\mathrm{b}}, n(\%)$ & $31(17.0)$ & $42(20.3)$ & $244(31.6)$ & $233(22.3)$ \\
\hline Duration of T2D (years), mean (SD) & $9.7(6.8)$ & $9.5(6.8)$ & $7.6(6.3)^{\mathrm{a}}$ & $6.3(5.5)^{\mathrm{a}}$ \\
\hline $\mathrm{HbA}_{1 \mathrm{c}}(\%)$, mean $(\mathrm{SD})$ & $8.3(0.8)$ & $8.5(0.9)$ & $8.5(1.1)$ & $8.4(1.1)$ \\
\hline \multirow[t]{2}{*}{$\mathrm{FPG}(\mathrm{mg} / \mathrm{dL})$, mean $(\mathrm{SD})$} & $168(46.7)$ & $176(50.2)$ & $172(50.0)$ & $171(46.8)$ \\
\hline & $n=181$ & $n=203$ & $n=751$ & $n=1026$ \\
\hline \multicolumn{5}{|l|}{ Baseline anti-hyperglycaemic drugs, $n(\%)^{c}$} \\
\hline None & $8(4.4)$ & $34(16.4)$ & $135(17.5)$ & $299(28.7)$ \\
\hline Metformin & $155(85.2)$ & $159(72.5)$ & $529(68.5)$ & $647(62.0)$ \\
\hline Sulfonylureas & $4(2.2)$ & $10(4.8)$ & $55(7.1)$ & $55(5.3)$ \\
\hline
\end{tabular}


Table 1 continued

\begin{tabular}{|c|c|c|c|c|}
\hline \multirow[t]{2}{*}{ Characteristic } & \multicolumn{2}{|l|}{ CKD3 } & \multicolumn{2}{|l|}{ CKD2 } \\
\hline & $\begin{array}{l}\text { EQW } \\
(N=182)\end{array}$ & $\begin{array}{l}\text { All comparators } \\
(N=\mathbf{2 0 7})\end{array}$ & $\begin{array}{l}\text { EQW } \\
(N=772)\end{array}$ & $\begin{array}{l}\text { All comparators } \\
(N=1043)\end{array}$ \\
\hline Thiazolidinediones & $36(19.8)$ & $31(15.0)$ & $32(4.1)$ & $39(3.7)$ \\
\hline Insulin & $18(9.9)$ & $22(10.6)$ & $107(13.9)$ & $98(9.4)$ \\
\hline
\end{tabular}

$B M I$ Body mass index, $C K D$ chronic kidney disease, $C K D 2$ stage $2 \mathrm{CKD}, C K D 3$ stage $3 \mathrm{CKD}, D B P$ diastolic blood pressure, eGFR estimated glomerular filtration rate, $E Q W$ exenatide once weekly, $F P G$ fasting plasma glucose, $H b A_{1 c}$ glycated haemoglobin, $N$ number of participants in the pooled treatment group, $n$ number of participants in analysis, $S B P$ systolic blood pressure, $S D$ standard deviation, $T 2 D$ type 2 diabetes, $u A C R$ urinary albumin-to-creatinine ratio

${ }^{a}$ One participant had no result

b uACR was not determined in two studies (DURATION-7 and DURATION-8)

c One additional participant took repaglinide (EQW, CKD2), which was not a permitted background anti-hyperglycaemic drug per the protocol

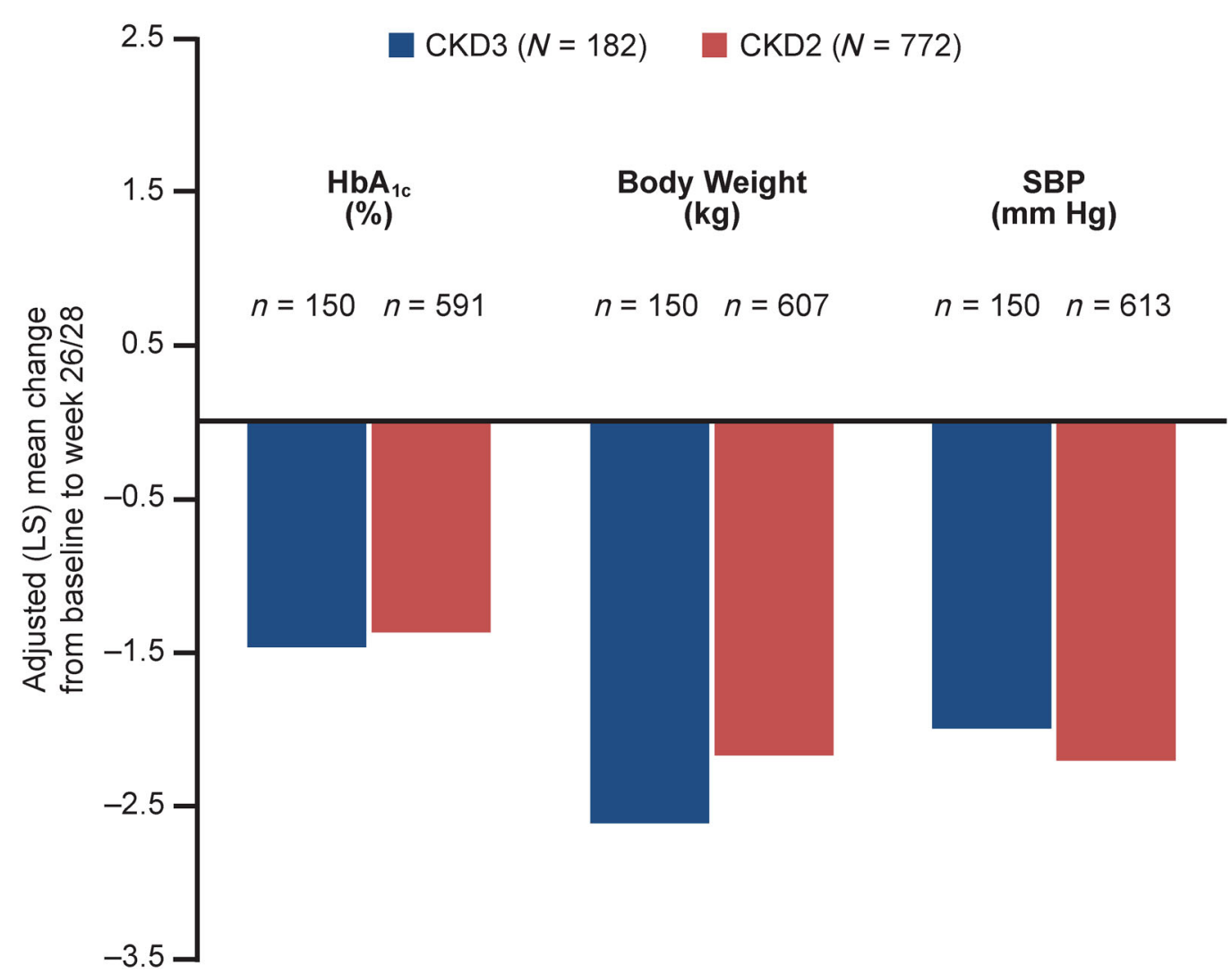

Fig. 1 Analysis of covariance-adjusted mean change in $\mathrm{HbA}_{1 \mathrm{c}}$, body weight and SBP from baseline to week 26/28 for participants with type 2 diabetes treated with EQW, by baseline CKD category (8-study pool [intention-to-treat analysis set]). $C K D$ chronic kidney disease, $C K D 2$ stage 2 $\mathrm{CKD}, C K D 3$ stage $3 \mathrm{CKD}, E Q W$ exenatide once weekly,
$H b A_{1 c}$ glycated haemoglobin, $L S$ least squares, $N$ number of participants in the pooled treatment group, $n$ number of participants with observed baseline and week 26 or 28 values, $S B P$ systolic blood pressure. Change from baseline to week $26 / 28=$ (week $26 / 28$ post-baseline value baseline value) 


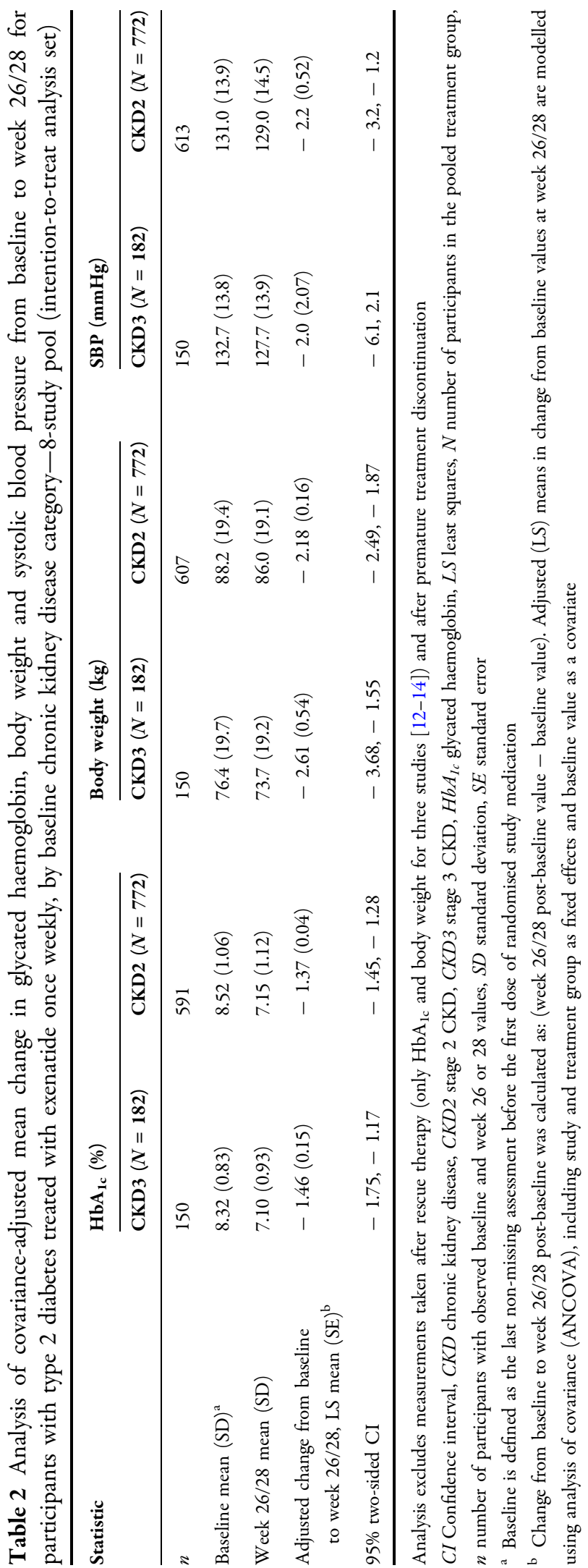

Safety

As shown in Table 3, a higher proportion of participants were reported as having any $\mathrm{AE}$ in the CKD3 subgroup (81\% [EQW] and 74\% [all comparators]) than in the CKD2 subgroup (72\% [EQW] and 68\% [all comparators]), irrespective of the treatment.

The frequencies and types of serious AEs (SAEs) were low and similar across treatment groups and between the CKD3 and CKD2 subgroups (CKD3: EQW 3\% and all comparators 6\% of participants; CKD2: EQW 3\% and all comparators $5 \%$ of participants).

AEs leading to discontinuation of study treatment were reported for $8 \%$ of participants in the EQW group and $4 \%$ of participants in the all comparators group in the CKD3 subgroup, and for $5 \%$ and $2 \%$, respectively, in the CKD2 subgroup.

A larger proportion of participants receiving EQW with CKD3 than those with CKD2 were reported to experience gastrointestinal disorders (42.2\% [CKD3] and 32.8\% [CKD2] for EQW; $18.6 \%$ [CKD3] and 18.8\% [CKD2] for all comparators); however, similar proportions were reported to experience nausea $(16.0 \%$ [CKD3] and $15.6 \%$ [CKD2] for EQW; 3.3\% [CKD3] and $4.9 \%$ [CKD2] for all comparators) and vomiting (7.5\% [CKD3] and 6.1\% [CKD2] for EQW; $2.9 \%$ [CKD3] and 2.3\% [CKD2] for all comparators). The term related to gastrointestinal disorders with the largest variation between the two CKD subgroups was abdominal discomfort, which was recorded in $5.9 \%(\mathrm{CKD} 3)$ and $0.9 \%(\mathrm{CKD} 2)$ of the participants receiving EQW.

There were no cases of dehydration in any group.

Overall, five participants experienced any AE potentially related to acute renal failure; however, only two participants had an SAE of acute kidney injury.

EQW treatment was also not associated with an increase in hypoglycaemic events in participants in the CKD3 subgroup compared with the CKD2 subgroup.

Renal function, as evaluated by eGFR, changed over time on average, with a similar magnitude in the EQW group as in the all comparators group in both CKD subgroups. The 
Table 3 Safety parameters and adverse events of special interest for participants with type 2 diabetes, by baseline chronic kidney disease category-8-study pool (safety analysis set)

\begin{tabular}{|c|c|c|c|c|}
\hline \multirow[t]{3}{*}{ Parameter or SMQ/preferred term ${ }^{a}$} & \multicolumn{4}{|c|}{ AE incidence rate, $n$ (\%) of participants } \\
\hline & \multicolumn{2}{|l|}{$\overline{\mathrm{CKD3}}$} & \multicolumn{2}{|l|}{ CKD2 } \\
\hline & $\begin{array}{l}\mathrm{EQW} \\
(N=187)\end{array}$ & $\begin{array}{l}\text { All comparators } \\
(N=210)\end{array}$ & $\begin{array}{l}\mathrm{EQW} \\
(N=784)\end{array}$ & $\begin{array}{l}\text { All comparators } \\
(N=1063)\end{array}$ \\
\hline Any AE & $151(80.7)$ & $155(73.8)$ & $567(72.3)$ & $727(68.4)$ \\
\hline $\begin{array}{l}\text { Any AE leading to discontinuation of } \\
\text { treatment }^{b}\end{array}$ & $15(8.0)$ & $8(3.8)$ & $39(5.0)$ & $23(2.2)$ \\
\hline Any AE with outcome of death & $1(0.5)$ & 0 & $1(0.1)$ & $3(0.3)$ \\
\hline Any SAE & $5(2.7)$ & $13(6.2)$ & $27(3.4)$ & $52(4.9)$ \\
\hline Acute kidney injury & $1(0.5)$ & 0 & 0 & $1(0.1)$ \\
\hline $\begin{array}{l}\text { Any SAE leading to discontinuation of } \\
\text { treatment }\end{array}$ & $3(1.6)$ & $4(1.9)$ & $7(0.9)$ & $6(0.6)$ \\
\hline \multicolumn{5}{|l|}{ AESI } \\
\hline Gastrointestinal disorders $(\mathrm{SOC})^{\mathrm{c}}$ & $79(42.2)$ & $39(18.6)$ & $257(32.8)$ & $200(18.8)$ \\
\hline Nausea & $30(16.0)$ & $7(3.3)$ & $122(15.6)$ & $52(4.9)$ \\
\hline Diarrhoea & $22(11.8)$ & $12(5.7)$ & $72(9.2)$ & $58(5.5)$ \\
\hline Constipation & $17(9.1)$ & $5(2.4)$ & $48(6.1)$ & $28(2.6)$ \\
\hline Vomiting & $14(7.5)$ & $6(2.9)$ & $48(6.1)$ & $24(2.3)$ \\
\hline Abdominal discomfort & $11(5.9)$ & $3(1.4)$ & $7(0.9)$ & $3(0.3)$ \\
\hline Dyspepsia & $7(3.7)$ & $1(0.5)$ & $21(2.7)$ & $21(2.0)$ \\
\hline GORD & $5(2.7)$ & $2(1.0)$ & $13(1.7)$ & $6(0.6)$ \\
\hline Flatulence & $4(2.1)$ & $1(0.5)$ & $11(1.4)$ & $5(0.5)$ \\
\hline Eructation & $4(2.1)$ & 0 & $7(0.9)$ & 0 \\
\hline Abdominal pain & $3(1.6)$ & $2(1.0)$ & $16(2.0)$ & $13(1.2)$ \\
\hline Abdominal distension & $1(0.5)$ & $1(0.5)$ & $16(2.0)$ & $7(0.7)$ \\
\hline Dehydration (SMQ narrow) AEs ${ }^{\mathrm{d}}$ & 0 & 0 & 0 & 0 \\
\hline $\begin{array}{l}\text { Acute renal failure (SMQ narrow) } \\
\mathrm{AEs}^{\mathrm{e}}\end{array}$ & $1(0.5)$ & 0 & $1(0.1)$ & $3(0.3)$ \\
\hline Acute kidney injury & $1(0.5)$ & 0 & 0 & $1(0.1)$ \\
\hline Renal failure & 0 & 0 & $1(0.1)$ & $2(0.2)$ \\
\hline Any hypoglycaemia & $19(10.2)$ & $49(23.3)$ & $109(13.9)$ & $157(14.8)$ \\
\hline Major hypoglycaemia & $1(0.5)$ & 0 & 0 & $1(0.1)$ \\
\hline Minor hypoglycaemia & $3(1.6)$ & $14(6.7)$ & $37(4.7)$ & $50(4.7)$ \\
\hline
\end{tabular}


Table 3 continued

\begin{tabular}{|c|c|c|c|c|}
\hline \multirow[t]{3}{*}{ Parameter or SMQ/preferred term ${ }^{a}$} & \multicolumn{4}{|c|}{ AE incidence rate, $n(\%)$ of participants } \\
\hline & \multicolumn{2}{|l|}{$\overline{\text { CKD3 }}$} & \multicolumn{2}{|l|}{ CKD2 } \\
\hline & $\begin{array}{l}\text { EQW } \\
(N=187)\end{array}$ & $\begin{array}{l}\text { All comparators } \\
(N=210)\end{array}$ & $\begin{array}{l}\text { EQW } \\
(N=784)\end{array}$ & $\begin{array}{l}\text { All comparators } \\
(N=1063)\end{array}$ \\
\hline Other & $17(9.1)$ & $45(21.4)$ & $93(11.9)$ & $130(12.2)$ \\
\hline
\end{tabular}

AEs are presented as $n$ (\%) of participants; 26- or 28-week treatment period AEs occur on or after first randomised study drug dose day through to end of controlled treatment period. Participants with multiple events are counted once per category but can be counted in more than one category

$A E$ Adverse event, AESI AE of special interest, CKD chronic kidney disease, CKD2 stage $2 \mathrm{CKD}, C K D 3$ stage $3 \mathrm{CKD}$, $E Q W$ exenatide once weekly, GORD gastro-oesophageal reflux disease, MedDRA Medical Dictionary for Regulatory Activities, $N$ number of participants in the pooled treatment group, $n$ number of participants in analysis, $S A E$ serious AE, $S M Q$ Standardised MedDRA Query, SOC system organ class

${ }^{a}$ MedDRA version 21.1 (https://www.meddra.org/) was used for AE coding

b AEs leading to discontinuation from study (all eight studies) and AEs leading to discontinuation of study treatment (D5553C00003, D5553C00002) [12, 14]

c Only preferred terms with rates $\geq 2.0 \%$ in any subgroup are shown

${ }^{d}$ Includes six preferred terms in SMQ search; only those with any incidence are shown

e Includes 18 preferred terms in SMQ search; only those with any incidence are shown

difference in adjusted mean change from baseline to week $26 / 28$ between the EQW and the all comparators group was $0.8 \mathrm{~mL} / \mathrm{min} / 1.73 \mathrm{~m}^{2}$ $(95 \% \mathrm{CI}-2.4,4.0)$ for the CKD3 subgroup and - $0.9 \mathrm{~mL} / \mathrm{min} / 1.73 \mathrm{~m}^{2}(95 \% \mathrm{CI}-2.4,0.6)$ for the CKD2 subgroup.

The proportion of participants experiencing a post-baseline increase in serum creatinine $\geq 1.5$-fold the baseline value was low and similar in participants receiving EQW in the CKD3 and CKD2 subgroups (Table 4). Median change from baseline to week $26 / 28$ in the urinary albumin-to-creatinine ratio for participants receiving EQW was $-3.5 \mathrm{mg} / \mathrm{g}$ in the CKD3 subgroup and $-2.7 \mathrm{mg} / \mathrm{g}$ in the CKD2 subgroup. Overall, treatment with EQW did not result in worsening of the renal function in either CKD subgroup.

For EQW participants, small mean increases in heart rate were observed in both CKD subgroups (Table 4).

\section{DISCUSSION}

This analysis of the pooled results of eight studies reporting on treatment with EQW over approximately 6 months showed EQW to be well tolerated in participants with type 2 diabetes and mild, as well as moderate, renal disease. Further, the mean results showed EQW to have clinically meaningful improvements in $\mathrm{HbA}_{1 \mathrm{c}}$ in both participants with CKD3 and $\mathrm{CKD} 2$, i.e. irrespective of renal function in patients with an eGFR $\geq 30 \mathrm{~mL} / \mathrm{min} / 1.73 \mathrm{~m}^{2}$.

Approximately one fifth of people with type 2 diabetes have comorbid CKD (defined as stages 3-5 or dialysis) [19], with up to one third of these developing CKD over a 4-year period [20]. These data underscore the importance of treatment options that can be safely and effectively used in this population. Previous studies have found that in mild or moderate renal impairment, no dosage adjustments of exenatide are needed [21], although reduced renal clearance leading to poor gastrointestinal tolerability limits its use in severe renal impairment (creatinine clearance $<30 \mathrm{~mL} / \mathrm{min}$ ) or end-stage renal disease [21]. Other GLP-1 RAs, such as albiglutide, dulaglutide and liraglutide, are not dependent on renal clearance for their degradation [22]. However, care still needs to be taken regarding their gastrointestinal 
Table 4 Descriptive results of changes in laboratory and clinical parameters from baseline to week 26/28 for participants with type 2 diabetes, by baseline chronic kidney disease category-8-study pool (safety analysis set)

\begin{tabular}{|c|c|c|c|c|}
\hline \multirow[t]{2}{*}{ Parameter } & \multicolumn{2}{|l|}{ CKD3 } & \multicolumn{2}{|l|}{ CKD2 } \\
\hline & $\begin{array}{l}\text { EQW } \\
(N=187)\end{array}$ & $\begin{array}{l}\text { All } \\
\text { comparators } \\
(N=210)\end{array}$ & $\begin{array}{l}\text { EQW } \\
(N=784)\end{array}$ & $\begin{array}{l}\text { All } \\
\text { comparators } \\
(N=1063)\end{array}$ \\
\hline $\begin{array}{l}\text { eGFR }\left(\mathrm{mL} / \mathrm{min} / 1.73 \mathrm{~m}^{2}\right) \text { at baseline, mean } \\
(\mathrm{SD})^{\mathrm{a}}\end{array}$ & $52.6(5.6)$ & $53.3(5.1)$ & $75.9(8.4)$ & $76.0(8.6)$ \\
\hline \multirow[t]{2}{*}{ Change from baseline, mean (SD) } & $9.3(13.9)$ & $7.9(14.8)$ & $2.5(16.0)$ & $3.4(13.7)$ \\
\hline & $n=147$ & $n=167$ & $n=575$ & $n=769$ \\
\hline $\begin{array}{l}\text { Serum creatinine } \geq 1.5 \text {-fold baseline value, } \\
\quad n(\%)^{\mathrm{b}}\end{array}$ & $2(1.1)$ & $1(0.5)$ & $11(1.4)$ & $7(0.7)$ \\
\hline \multirow{3}{*}{$\begin{array}{l}\mathrm{uACR}(\mathrm{mg} / \mathrm{g}) \text { at baseline, median (minimum, } \\
\text { maximum) }\end{array}$} & 14.2 & 20.4 & 10.6 & 10.6 \\
\hline & $(0.9,2938.0)$ & $(0.9,4211.7)$ & $(0.9,1991.1)$ & $(0.9,2178.0)$ \\
\hline & $n=156$ & $n=167$ & $n=538$ & $n=825$ \\
\hline \multirow{3}{*}{$\begin{array}{l}\text { Change from baseline }(\mathrm{mg} / \mathrm{g}) \text {, median } \\
\text { (minimum, maximum) }\end{array}$} & -3.5 & -2.7 & -2.7 & -0.9 \\
\hline & $\begin{array}{c}(-1315.3 \\
9893.7)\end{array}$ & $\begin{array}{l}(-1098.3,736.9) \\
n=134\end{array}$ & $\begin{array}{l}(-744.0 \\
534.1)\end{array}$ & $\begin{array}{l}(-1105.4 \\
1004.4)\end{array}$ \\
\hline & $n=119$ & & $n=364$ & $n=565$ \\
\hline Heart rate $(\mathrm{bpm})$ at baseline, mean $(\mathrm{SD})$ & $74.7(11.6)$ & $73.9(10.9)$ & $74.4(9.8)$ & $73.7(10.1)$ \\
\hline \multirow[t]{2}{*}{ Change from baseline (bpm), mean (SD) } & $4.2(10.7)$ & $0.6(7.7)$ & $2.7(10.0)$ & $-0.3(9.5)$ \\
\hline & $n=150$ & $n=173$ & $n=614$ & $n=818$ \\
\hline
\end{tabular}

bpm Beats per minute, $C K D$ chronic kidney disease, $C K D 2$ stage 2 CKD, CKD3 stage $3 \mathrm{CKD}$, eGFR estimated glomerular filtration rate, $E Q W$ exenatide once weekly, $N$ number of participants in the pooled treatment group, $n$ number of participants in analysis, $S D$ standard deviation, $u A C R$ urinary albumin-to-creatinine ratio

a eGFR for all studies was calculated on the basis of the 4-variable Modification of Diet in Renal Disease equation: $175 \times$ serum creatinine $(\mathrm{mg} / \mathrm{dL})^{-1.154} \times$ Age $(\text { years) })^{-0.203} \times 1.212$ (black) $\times 0.742$ (women) except for study H8O-JEGWBX [15], which used the 3-variable Japanese equation: $194 \times$ serum creatinine $(\mathrm{mg} / \mathrm{dL})^{-1.094} \times$ Age $(\text { years })^{-0.287} \times$ 0.739 (women)

b Serum creatinine value $\geq 1.5$-fold the baseline value at any time during the $26 / 28$-week controlled treatment period

tolerability profiles and the risk for dehydration and potential subsequent acute kidney injury.

The safety and efficacy results of this pooled analysis are consistent with those of the individual studies included herein [9-16] and with other pooled analyses of EQW [23, 24]. Although EQW was generally well tolerated in participants with CKD3, the proportion of participants who discontinued due to an $\mathrm{AE}$ was slightly higher for participants with CKD3 (8\%) than for those with CKD2 (5\%), largely attributable to gastrointestinal disorders, and possibly because this is a population with more comorbidities. These rates were also respectively higher than those in participants with CKD3 (4\%) and CKD2 (2\%) receiving comparator drugs. A higher proportion of participants were reported to have any $\mathrm{AE}$ in the $\mathrm{CKD} 3$ than in the CKD2 subgroup, irrespective of treatment group. Overall, the rates of any gastrointestinal 
disorder by system organ class were higher in participants receiving EQW than in those receiving comparator drugs or placebo. Moreover, the rates were higher in participants receiving EQW in the CKD3 subgroup compared with the CKD2 subgroup. However, the proportion of participants receiving EQW who experienced nausea was similar in the CKD3 and CKD2 subgroups (approx. 16\%), as was that of vomiting (approx. 6-8\%). The events most responsible for the difference in gastrointestinal tolerability between the EQW CKD subgroups were related to abdominal discomfort and constipation. Analyses evaluating the time-course of gastrointestinal AEs associated with EQW treatment indicate that the rate of these events diminishes over time $[23,25]$ and that no dose titration is needed upon treatment introduction due to the slow release of active drug from the extended-release formulation.

Frequencies for nausea and vomiting for GLP-1 RAs that are not dependent on renal filtration for their clearance have also been examined in people with CKD. In the LIRARENAL study [26], which examined the efficacy and safety of liraglutide $1.8 \mathrm{mg} /$ day, and the PIONEER 5 [27], which looked at the efficacy and safety of oral semaglutide up to $14 \mathrm{mg}$ /day, participants with uncontrolled type 2 diabetes and CKD3 treated for 26 weeks experienced nausea $(21.4 \%$ and $19 \%$, respectively) and vomiting (12.1\% and $12 \%$, respectively). In the AWARD-7 study, dulaglutide was examined in a 52-week trial in participants with moderate to severe CKD. Participants receiving the lower dulaglutide dose of 0.75 -mg once weekly experienced nausea (14\%) and vomiting (8\%), with substantially higher incidences reported with the $1.5-\mathrm{mg} /$ once-weekly dose [28].

The current analysis has several strengths, such as inclusion of several individual studies that randomised collectively a wide variety of people with type 2 diabetes. Moreover, this analysis has a strong representation of Asian participants, a population that is often underrepresented in existing GLP-1 RA studies. The analysis thus provides data in this group of individuals who, because of pathophysiological differences (such as type 2 diabetes that is primarily characterised by beta-cell dysfunction as opposed to insulin resistance [29]) and generally a lower body weight, may respond differently to GLP-1 RAs. However, the large proportion of Japanese participants in our analysis could also be considered a limitation as study heterogeneity could potentially skew the results. Other limitations include the fact that the study duration was only approximately 6 months, thus diminishing the possibility of detecting rare AEs or AEs that could develop or be detected over a longer time. By contrast, the 6-month period should have been long enough to fully describe any differences in gastrointestinal tolerability or volume depletion due to differences in renal function and drug clearance. In addition, the current pooled analysis gives a valuable opportunity for a more detailed study of the gastrointestinal AE profile in people with renal impairment, whereas the large-scale cardiovascular outcome trial, EXSCEL, gave a clear indication of long-term cardiovascular safety also in the pre-defined subgroup of participants receiving EQW with eGFR below $60 \mathrm{~mL} / \mathrm{min} / 1.73 \mathrm{~m}^{2}$ [8].

\section{CONCLUSIONS}

The pooled results of eight studies show that EQW treatment in participants with type 2 diabetes with CKD3 (moderate renal impairment), as well as in those with CKD2 (mild renal impairment), is well tolerated, with results consistent with EQW's established safety profile. Efficacy improvements, including changes in $\mathrm{HbA}_{1 \mathrm{c}}$, body weight and SBP, were consistent with the known treatment effects of the drug and were generally similar between participants with CKD3 and CKD2.

\section{ACKNOWLEDGEMENTS}

Funding. This study was funded by AstraZeneca Pharmaceuticals LP, who also funded the Rapid Service Fee.

Medical Writing, Editorial and Other Assistance. Kelly Felty (Clinical Programming 
Solutions, Inc.) and Kevin Kelly (SAS Biopharm Ltd), funded by AstraZeneca, created the analysis datasets and analysis programs, and programmed the tables for the eGFR subgroup analyses. Medical writing assistance, funded by AstraZeneca, was provided by Steven Tresker of Cactus Life Sciences (part of Cactus Communications). We thank all the investigators, coordinators, study staff and patients participating in the eight RCTs included in this analysis.

Authorship. All named authors meet the International Committee of Medical Journal Editors (ICMJE) criteria for authorship of this article, take responsibility for the integrity of the work as a whole, and have given their approval for this version to be published.

Prior Presentation. This analysis was previously presented in part in abstract form at the American Diabetes Association's 79th Scientific Sessions (ADA 2019), San Francisco, California, USA, 7-11 June 2019, and as a poster presentation at the 55th Annual Meeting of the European Association for the Study of Diabetes (EASD 2019), Barcelona, Spain, 16-20 September 2019.

Disclosures. Cristian Guja has participated in scientific advisory boards and received consulting fees from AstraZeneca, Boehringer Ingelheim, Egis, Eli Lilly, MSD, Novo Nordisk, Sanofi and Zentiva. Juan P. Frías has received research support from AbbVie, Allergan, AstraZeneca, Boehringer Ingelheim, Bristol-Myers Squibb, Eli Lilly, Enanta, Janssen, Merck, Novartis, Novo Nordisk, Pfizer, Sanofi and Theracos; has participated in the scientific advisory boards for and received consulting fees from AstraZeneca, Boehringer Ingelheim, Bristol-Myers Squibb, Eli Lilly, Merck, Novo Nordisk and Sanofi; and is involved in the speakers' bureau for Merck and Sanofi. Lisa Suchower is an employee of Kelly Services for AstraZeneca, a former employee of AstraZeneca and a stockholder of AstraZeneca, Merck and Express Scripts. Elise Hardy, Galina Marr and C. David Sjöström are employees of and own stock in AstraZeneca. Serge A. Jabbour is a consultant for AstraZeneca, Eli Lilly and Janssen.
Compliance with Ethics Guidelines. All studies complied with the Helsinki Declaration of 1964 and its later amendments, and other relevant ethical guidelines, and all participants had provided written informed consent. Each study site involved in the eight studies received approval from their respective local ethics committees.

Data Availability. Data underlying the findings described in this article may be obtained in accordance with AstraZeneca's data sharing policy described at https:// astrazenecagrouptrials.pharmacm.com/ST/ Submission/Disclosure.

Open Access. This article is licensed under a Creative Commons Attribution-NonCommercial 4.0 International License, which permits any non-commercial use, sharing, adaptation, distribution and reproduction in any medium or format, as long as you give appropriate credit to the original author(s) and the source, provide a link to the Creative Commons licence, and indicate if changes were made. The images or other third party material in this article are included in the article's Creative Commons licence, unless indicated otherwise in a credit line to the material. If material is not included in the article's Creative Commons licence and your intended use is not permitted by statutory regulation or exceeds the permitted use, you will need to obtain permission directly from the copyright holder. To view a copy of this licence, visit http://creativecommons.org/licenses/by$\mathrm{nc} / 4.0 /$.

\section{REFERENCES}

1. Shahbazian H, Rezaii I. Diabetic kidney disease; review of the current knowledge. J Renal Inj Prev. 2013;2:73-80.

2. Heimbürger SM, Brønden A, Johansen NJ, Dejgaard TF, Vilsbøll T, Knop FK. The efficacy and safety of exenatide once weekly in patients with type 2 diabetes. Expert Opin Pharmacother. 2019;20:501-10.

3. European Medicines Agency. Bydureon. Summary of product characteristics. Södertälje, Sweden: 
AstraZeneca AB; 2019. https://www.ema.europa.eu/ en/documents/product-information/bydureonepar-product-information_en.pdf. Accessed 22 Jan 2020.

4. Wysham C, Grimm M, Chen S. Once weekly exenatide: efficacy, tolerability and place in therapy. Diabetes Obes Metab. 2013;15:871-81.

5. Federal Drug Administration. Bydureon ${ }^{\circledR}$ BCise $^{\mathrm{TM}}$ prescribing information. Wilmington, DE: AstraZeneca Pharmaceuticals LP; 2019. https://www. accessdata.fda.gov/drugsatfda_docs/label/2017/ 209210s000lbl.pdf. Accessed 22 Jan 2020.

6. Therapeutic Goods Administration. BYDUREON product information. West Ryde, Australia: Eli Lilly Australia Pty. Limited; 2012. https://www.tga.gov. $\mathrm{au} /$ sites/default/files/auspar-exenatide-130205-pi. pdf. Accessed 22 Jan 2020.

7. Bethel MA, Mentz RJ, Merrill P, et al. Renal outcomes in the EXenatide study of cardiovascular event lowering (EXSCEL). Diabetes. 2018;67:522.

8. Holman RR, Bethel MA, Mentz RJ, et al. Effects of once-weekly exenatide on cardiovascular outcomes in type 2 diabetes. N Engl J Med. 2017;377:1228-39.

9. Bergenstal RM, Wysham C, Macconell L, et al. Efficacy and safety of exenatide once weekly versus sitagliptin or pioglitazone as an adjunct to metformin for treatment of type 2 diabetes (DURATION-2): a randomised trial. Lancet. 2010;376: 431-9.

10. Davies M, Heller S, Sreenan S, et al. Once-weekly exenatide versus once- or twice-daily insulin detemir: randomized, open-label, clinical trial of efficacy and safety in patients with type 2 diabetes treated with metformin alone or in combination with sulfonylureas. Diabetes Care. 2013;36:1368-76.

11. Diamant M, Van Gaal L, Guerci B, et al. Exenatide once weekly versus insulin glargine for type 2 diabetes (DURATION-3): 3-year results of an open-label randomised trial. Lancet Diabetes Endocrinol. 2014;2:464-73.

12. Frías JP, Guja C, Hardy E, et al. Exenatide once weekly plus dapagliflozin once daily versus exenatide or dapagliflozin alone in patients with type 2 diabetes inadequately controlled with metformin monotherapy (DURATION-8): a 28 week, multicentre, double-blind, phase 3, randomised controlled trial. Lancet Diabetes Endocrinol. 2016;4:1004-16.

13. Gadde KM, Vetter ML, Iqbal N, Hardy E, Öhman P, DURATION-NEO-2 study investigators. Efficacy and safety of autoinjected exenatide once-weekly suspension versus sitagliptin or placebo with metformin in patients with type 2 diabetes: the
DURATION-NEO-2 randomized clinical study. Diabetes Obes Metab. 2017;19:979-88.

14. Guja C, Frías JP, Somogyi A, et al. Effect of exenatide QW or placebo, both added to titrated insulin glargine, in uncontrolled type 2 diabetes: the DURATION-7 randomized study. Diabetes Obes Metab. 2018;20:1602-14.

15. Inagaki N, Atsumi $Y$, Oura T, Saito H, Imaoka T. Efficacy and safety profile of exenatide once weekly compared with insulin once daily in Japanese patients with type 2 diabetes treated with oral antidiabetes drug(s): results from a 26-week, randomized, openlabel, parallel-group, multicenter, noninferiority study. Clin Ther. 2012;34:1892-908.e1.

16. Russell-Jones D, Cuddihy RM, Hanefeld M, et al. Efficacy and safety of exenatide once weekly versus metformin, pioglitazone, and sitagliptin used as monotherapy in drug-naive patients with type 2 diabetes (DURATION-4): a 26-week double-blind study. Diabetes Care. 2012;35:252-8.

17. Levey AS, Coresh J, Greene T, et al. Using standardized serum creatinine values in the modification of diet in renal disease study equation for estimating glomerular filtration rate. Ann Intern Med. 2006; 145:247-54.

18. Matsuo S, Imai E, Horio M, et al. Revised equations for estimated GFR from serum creatinine in Japan. Am J Kidney Dis. 2009;53:982-92.

19. Arnold SV, Kosiborod M, Wang J, Fenici P, Gannedahl G, LoCasale RJ. Burden of cardio-renal-metabolic conditions in adults with type 2 diabetes within the Diabetes Collaborative Registry. Diabetes Obes Metab. 2018;20:2000-3.

20. De Cosmo S, Viazzi F, Pacilli A, et al. Predictors of chronic kidney disease in type 2 diabetes: a longitudinal study from the AMD Annals initiative. Medicine (Baltimore). 2016;95:e4007.

21. Linnebjerg H, Kothare PA, Park S, et al. Effect of renal impairment on the pharmacokinetics of exenatide. Br J Clin Pharmacol. 2007;64:317-27.

22. Davies M, Chatterjee S, Khunti K. The treatment of type 2 diabetes in the presence of renal impairment: what we should know about newer therapies. Clin Pharmacol. 2016;8:61-81.

23. MacConell L, Gurney K, Malloy J, Zhou M, Kolterman O. Safety and tolerability of exenatide once weekly in patients with type 2 diabetes: an integrated analysis of 4,328 patients. Diabetes Metab Syndr Obes. 2015;8:241-53.

24. Trautmann ME, Van Gaal L, Han J, Hardy E. Threeyear efficacy and safety of exenatide once weekly: a 
pooled analysis of three trials. J Diabetes Compl. 2017;31:1415-22.

25. Genovese S, Mannucci E, Ceriello A. A review of the long-term efficacy, tolerability, and safety of exenatide once weekly for type 2 diabetes. Adv Ther. 2017;34:1791-814.

26. Davies MJ, Bain SC, Atkin SL, et al. Efficacy and safety of liraglutide versus placebo as add-on to glucose-lowering therapy in patients with type 2 diabetes and moderate renal impairment (LIRARENAL): a randomized clinical trial. Diabetes Care. 2016;39:222-30.

27. Mosenzon O, Blicher TM, Rosenlund S, et al. Efficacy and safety of oral semaglutide in patients with type 2 diabetes and moderate renal impairment (PIONEER 5): a placebo-controlled, randomised, phase 3a trial. Lancet Diabetes Endocrinol. 2019;7: 515-27.

28. Tuttle KR, Lakshmanan MC, Rayner B, et al. Dulaglutide versus insulin glargine in patients with type 2 diabetes and moderate-to-severe chronic kidney disease (AWARD-7): a multicentre, open-label, randomised trial. Lancet Diabetes Endocrinol. 2018;6:605-17.

29. Yabe D, Seino Y, Fukushima M, Seino S. $\beta$ cell dysfunction versus insulin resistance in the pathogenesis of type 2 diabetes in East Asians. Curr Diab Rep. 2015;15:602. 